\title{
HONOUR IN DIFFERENT CULTURES AND LEGAL SYSTEMS
}

\author{
Christian Giordano*
}

\begin{abstract}
This article intends to point up characteristics shared by societies in which honour still retains a major social significance. These affinities must obviously not be regarded as cultural constants but rather as 'family resemblances' between analogous yet distinct socio-cultural phenomena. Unlike most authors who represent honour as the expression of specific moral values or religious belonging, this article endeavours to highlight the importance of transactional and interactional social aspects that characterise the ongoing rivalries, tensions and conflicts between groups and individuals with a view to confirm their own status, prestige and reputation. Under this aspect, the struggle for the recognition and permanent management of one's own social standing or class-belonging becomes crucial, not least because status, prestige and reputation ultimately grant easier access to economic resources. Symbolic capital grounded in honour can be turned into economic capital, while loss of honour may lead to being excluded from activities that guarantee forms of prosperity, albeit limited. This point of view allows explaining phenomena deemed criminal, such as 'honour killings', while avoiding any ethnocentric prejudice.
\end{abstract}

\section{Introduction}

After nearly 20 years of oblivion, recurrent cases of 'honour killings' in the immigrant communities of several Western European societies have once again brought to the fore the theme of honour. Since these crimes were committed by Muslim social actors, some experts on this issue have formulated a simplistic equation between the concept of honour and Islam. Given his experience as a forensic anthropology expert, this writer has always challenged this statement because he has repeatedly dealt with court cases involving people from other religions. ${ }^{1}$

Undeniably, however, in Europe the number of Muslim immigrants involved in criminal cases regarding matters of honour is statistically significant. This article, though, intends to prove that the social representations of honour and its resulting

* Prof. Dr Christian Giordano is Full Professor and Permanent Director of the Department of Social Anthropology in the University of Fribourg, Switzerland. 
social practices are not so much linked to a specific religious belief as much as to distinctive social structures (tribal or semi-tribal) and kinship systems as well as to the resulting power roles (often patriarchic) in societies where rivalries involving reputation, prestige, status and ultimately economic opportunities are crucial. Accordingly, in some cases religion can be an instrument, but never the actual underlying cause of conflicts of honour.

\section{The Concept of Honour: In Search of a Definition}

Of all anthropologists, probably Julian Pitt-Rivers is the one who sought to find an exhaustive definition of honour, though acknowledging that its characterisation has to consider various dimensions since the phenomenon is so complex. He suggests distinguishing the two following aspects: ${ }^{2}$

1. Honour can be understood as a feeling or, more accurately, a specific state of consciousness consisting in a certainty that there's nothing to be self-reproachful about and that consequently one can and indeed has a right to feel proud. This aspect considers only the 'individualistic' dimension, since the sole judge of one's own honour is the subject, that is, oneself. Besides, this characterisation smacks of a voluntaristic moral philosophy that social scientists cannot adopt unquestioningly.

2. The second aspect refers to concrete behaviour as a manifestation of the justmentioned state of consciousness. Therefore, this state is relevant only if courses of action are considered in relation to their reception and appraisal by the actor's own society. Consequently, honour has always something to do with demonstration, competition, and above all reputation.

This view is ultimately held by Peristiany, too, who describes honour as one of the "universal aspects of social evaluation". ${ }^{3}$ According to Peristiany's generalising perspective, the actor who makes a claim to honour must display specific acquired and/or ascribed qualities. In other words, the actor has to comply with the strict, socially-guaranteed norms of a code acknowledged by the community.

\section{Honour as a Hierarchising Principle}

Anthropologists have repeatedly wondered whether conceptions of honour tend to favour an egalitarian or a hierarchical social order. In his monograph on a Spanish community, Lison-Tolosana, a typical representative of the first view, maintains that honour represents an egalitarian principle resting on parity between the "status of the powerful" and the "virtue of the weak". ${ }^{4}$ This line of reasoning is 
not very convincing because it suggests that societies are conflict-free formations characterised by the harmonious interaction of their members. However, both the representation of society and the social practices are anything but harmonious, although it must be conceded that antagonisms between conflicting groups are often defused by mediating mechanisms, such as the patronage system's patterns of thought and strategies.

In this specific context, therefore, Bailey's perspective can be considered more differentiated because this author defines reputation, thus also honour, as a competitive conduct "to remain equal". ${ }^{5}$ The struggle "to remain equal", however, is constantly neutralised by the claim to be socially superior. ${ }^{6}$ Accordingly, an egalitarian social order based on an even and fixed distribution of honour is regarded as an unattainable utopia. ${ }^{7}$ In the eyes of those involved, society is sharply divided into two groups the 'honourable' and the 'shameless' - and organised in a corresponding hierarchy. ${ }^{8}$

\section{Honour as Status and Reputation}

Honour as an "aspiration and validation of status" is redefined daily. Therefore, the reputation of a person and/or a group is not a constant: honour can grow, but can also be lost. Such a 'market quotation' of one's own honour, always subject to change, in extreme cases every day, produces fierce feelings of rivalry between groups and persons in terms of status.

Empirical evidence shows that societies in which the social logic of honour plays a major role are shaped by their conflictual character. In other words, these social formations may be defined as systems of social relations between competing individuals and groups in the public sphere. In this sense, these patterns of thought are constantly and almost obsessively dominated by the notion that society outside one's own group (for example family and kinfolk) is made up of potential rivals who must unconditionally be outdone. This is the only way to maintain and maximise honour, reputation, and status.

These observations indicate that honour and shame societies, which quite clearly - beyond any religious belonging - stretch from Latin America (Ecuador and Brazil in particular) to the entire Mediterranean basin and from the Middle East to Bangladesh, are permeated from top to bottom by a system of social relationships grounded in rivalry and conflict between individuals and groups. This is due to the simple fact that the major attribute of social prestige consists in displaying one's personal or collective ability to predominate on others in the public sphere.

The latter observation spells out the crux of the theme sketched in this section. Honour is an instrument of social differentiation because it is through honour that the never-ending attempt is made to document both personal superiority and that of one's own group in the social sphere. 
But the fierce competition for honour also implies an extraordinary fear of social demotion, which in turn is an indicator of the extremely developed attention to stratification and ultimately to hierarchical structure of members of these societies. The claim to social and moral superiority together with a fear of social decline, that is, honour as an instrument of social differentiation, considerably increases the importance of that social institution which in everyday language is called "public opinion'. It is precisely this "tremendous social pressure" that Laffin emphasises. ${ }^{10}$

The 'public opinion', which ultimately determines the position of individuals and groups in the social hierarchy based on their honour, also plays a prominent role as an organ of control in these cultures. 'Public opinion' constantly redefines the 'good name' of the honourable, just as subtle rumour establishes the 'shamelessness' of a person or a group. In societies where the importance of honour is crucial there are hardly more popular conversations than the ones dealing with the 'good name' of individuals and collectives. Correspondingly, rumour is a favoured strategy to undermine the reputation of potential rivals.

On the subject of honour as an instrument of social differentiation, the importance of the media through which 'public opinion' as social control articulates itself must also be stressed. There are specific social spaces in which the construction or destruction of reputation, of status and hence of honour is carried out. Here one's good name can be staged while the good name of others, especially rivals, is thoroughly scrutinised and examined. Simultaneously, in the very same social spaces, on the one hand rumours are circulated through gossip, and on the other rumours about victims are neutralised by those affected through exemplary behaviour.

As previously mentioned, in contests for honour as processes of social differentiation what is at issue is the achievement of a specific social position and its acknowledgement by other members of society. Neither the claim to social and moral superiority, nor the fear of social decline can be attributed solely to the effect or mechanical reproduction of handed-down models, since these attitudes are constitutive elements of a "politics of reputation", ${ }^{11}$ which is perceived as rational by the protagonists themselves and is based on the notion of a dichotomous division between 'honourable' and 'shameless'.

As an instrument of social differentiation, we can say that the actors conform in their behaviour not only because they have internalised the system of norms, but also in order to 'administer' their good name as skilfully as possible in the presence of the judging organs of social control. Accordingly, the actor does not have to be absolutely convinced of the moral rightness of the code of honour. What is more relevant to him is the acknowledgement of his own 'social identity'; i.e. the individual's actions and attributes that allows the 'public opinion' of the society in which he is living to recognise which position he occupies in the dichotomous order of the 'honourable' and the 'shameless'. 
Put more concretely: the actors feel and are considered dishonoured or 'shameless' only when the damage to honour becomes public. Likewise, the 'shameless' person will recover his honourableness only when he demonstrates publicly that he can defend his reputation after an affront. Whether this is a matter of fact or the product of an unfounded rumour is relatively unimportant. Members of these societies can certainly not be considered typical 'other directed' persons in Riesman's sense. With respect to honour, however, the extremely vigilant attention to one's own 'social identity' as a 'rational politics of reputation' is based on a meticulously exact emphasis on external formalities.

The outstanding significance of a 'politics of reputation' as a rational calculation for the skilful management of status, position, and honour, raises the question of the role of 'façade' or 'mask'. Accordingly, in the social logic of honour knowing how to safeguard the 'façade' is a definite plus, while letting the 'mask' fall because you're unable to keep it in place is a social disaster. Reference to the 'façade' or the 'mask' as a calculated presentation of self in public is further evidence that honour can never be based on the idea of an egalitarian social order, thus confirming the assumption that the actors themselves ultimately consider honour to be an instrument of social differentiation.

Thus far, honour has been investigated in relation to the struggle for reputation, status, and position. There could be a legitimate impression that the accent was on forms of competition, which could be defined as ideal, without having sufficiently taken into account the material implications of the phenomenon of honour. Thus, we must agree with Bourdieu when he states that honour represents a "symbolic capital", ${ }^{12}$ which can be invested in the material sector.

\section{Honour and Class Belonging}

The competition for honour is not between two or more arbitrary actors. Much the same is true of injuries to honour as well as subsequent revenge actions by the offended party. Empirical research and ethnographic material prove that competitive and conflict situations only arise when the social distance between the persons involved is not too great. Ultimately it is more or less inconceivable that a competition for honour will occur between a rich man and a poor man.

Pitt-Rivers has been the most careful investigator of this phenomenon and has established that in Andalusia, for example, there are several nuances of conceptions of honour, which also imply differing modes of conduct. ${ }^{13} \mathrm{He}$ also observed a very evident relation between conception of honour and class belonging. In terms of social history, the southern Spanish complex of honour - according to Pitt-Rivers - can be divided into at least three variants, approximately correlated with the area's traditional social hierarchy. Aristocracy, agrarian bourgeoisie, and rural lower 
orders had their specific understanding of honour: a state of affairs that still carries some weight today. ${ }^{14}$

\section{The Pervasive Conflictual Aspect of Honour and the Struggle for Recognition}

As mentioned before, a pervasive conflictual aspect characterising relations between individuals and groups is typical of societies where the social logic of honour plays a major role. This observation may be postulated via the formula created by Hegelian philosophy ${ }^{15}$ that has aptly been taken up again recently by Canadian philosopher Charles Taylor. Therefore, we can state that the social logic of honour is permanently linked with the struggle for recognition and, in the case in point, with the recognition of position, status and reputation of one's self or ourselves with reference to significant others. Yet, according to a modernistic conception of society, honour is not only an archaic phenomenon, but also an obstacle to social cohesion due precisely to the bitter struggles for recognition.

For this reason the prime movers of the French Revolution and their ideological descendants have sought to replace the social logic of honour with the one of dignity. Specifically in contrast with honour, dignity was described as a universal potential shared by all men. ${ }^{16}$ In principle at least, dignity should guarantee equal recognition and treatment (also before the law) to everyone since all human beings are entitled to the same respect. Instead, honour and its pervasive conflictual aspect engendered by the struggle for recognition produce a society composed of individuals or collectivities belonging to different categories, not to mention the distinction in this context between the honourable and the shameless.

Has the principle of dignity actually taken root in the socio-cultural context of late modernity? From a socio-anthropological point of view, we have to admit that the principle of dignity did not assert itself in modern societies as might have been expected; though an important idea, it turned out to be too abstract. ${ }^{17}$

Dignity has not taken the place of honour; therefore, to this day honour cannot be regarded as a relic of times past, but rather as a socio-cultural model that coexists and rivals with dignity. Since honour in modernity has not been replaced by dignity, as a too-narrow evolutionist scheme would have it, we can justifiably hypothesise the presence of a permanent dialectic between these two opposing paradigms of sociability, which ultimately furthers modern societies' dynamics. Dignity, therefore, can be interpreted as a necessary corrective that should be able to lessen conflicts by taking the edge off the struggles for recognition imposed by the antagonistic logic of honour. Perhaps we may hypothesise that the principle of dignity has somewhat curbed the conflictual aspect of honour based on the struggle for recognition, but it definitely has not eliminated it. 
Honour, therefore, cannot be downgraded to something archaic, obsolete, and dying out. Quite the opposite, instead, since honour is still a relevant way to express oneself and to act, though at first glance it may appear contrary or alien to the culture of modernity. Consequently, the rhetoric of honour, with its specific expressions such as "I give my word of honour" or "I swear upon my honour" or "lose one's face", and its equally specific terms such as honourable (i.e. respectable), honorary of office, to honour (in terms of respecting someone or something), dishonourable (in terms of behaviour) is still a feature of the public management of reputation (in everyday life, as well) even in societies that an ethnocentric vision purports to be the most advanced and modern ones.

A philology research carried out in Germany highlights that in that country's language the concept of honour appears in well over 150 everyday phrases. These expressions cannot be regarded as a set of hollow clichés that by now has lost meaning and social purpose. This observation is corroborated by the fact that the criminal codes of many States, unconditionally regarded as modern, include paragraphs on the offence to honour. Under this aspect, Germany and Switzerland are exemplary.

We also need to mention that in countries such as Italy and France up to a few decades ago the appalling honour killing was awarded preferential treatment with minor charges. Based on the doctrine of the Augustan lex Julia de adulteriis of 17 BCE, Zanardelli and Rocco, who drafted the Italian criminal code in force up to the early 1980s, introduced these magnanimous mitigating circumstances for honour crimes. This broadly lenient approach remained in force until Article 442 was promulgated in 1981. In France, laws concerning minor charges for honour killings were repealed only in 1975 with the criminal code revision. In Spain and Portugal, the decriminalisation of honour crimes as a customary legitimate sanction for adultery committed by one's wife was repealed even later, i.e., only after these countries revised their respective criminal codes in the mid-1980s.

Honour, therefore, cannot be viewed as a complex of archaic cultural phenomena belonging to the past that may be classified as dying out oddities. This certainly applies to societies that, rightly or not, are regarded as less modernised and more socially backward. Yet, most immigrant societies in Europe and North America have had to acknowledge that the cultural idiom of honour, along with its specific strategy actions, is still very relevant in significant communities that emigrated from the Mediterranean area and neighbouring regions, such as the Near and Middle East and Latin America. Especially the undeniable increase of illegal, thus of criminally relevant social practices such as honour crimes, has kindled an interest in behaviours that were regarded as definitively extinct. Honour, especially the one exported to immigrant societies, is once again a challenge for legal systems. 
In order to understand this reproduction we need to consider various aspects that sustain the persistence of action strategies linked to the concept of honour. Contrary to assimilationist and integrationist concepts, immigrants from whichever country do not change their cultural identity in toto by taking on the values, rules and social practices of the society of residence for the simple reason that, since they are experiencing a social and cultural transnational condition, they maintain actual and affective ties with their society of origin. Contacts with the country of origin have become easier and more affordable in the current era of globalisation thanks to computer technology, mobile phones and low-cost flights. Seasonal returns on vacation are no longer a dream, but rather a regular event, which, especially for immigrants from the Mediterranean and contiguous areas, occurs once or even more times a year. During these stays in their society of origin even second- or thirdgeneration immigrants will find, rediscover and come in close contact with their culture of origin's social strategies, such as the ones linked to honour. Paradoxically enough, the opportunities created by globalisation itself, which according to some social scientists would have created a worldwide, quasi-homogeneous culture along the lines of the western one, ${ }^{18}$ have allowed the persistence of the code of honour of Mediterranean and contiguous societies in the immigrants' countries of residence.

Contrary to the expectations of researchers who explicitly or implicitly turn to methodological individualism, and which Bourdieu has rightly condemned as an intellectualistic attitude due to its inherent voluntarism, ${ }^{19}$ immigrants, especially those from regions on Europe's margins or beyond, usually will not act as isolated individuals, but rather in accordance with family or relatives' collective logics and will organise into diaspora-like ethnic communities. To some extent, family or relatives' communities abide by ancestral canons still in force in the societies of origin, which are based on the notion of honour peculiar to one's own group. Even diasporas emerge as places where cultural traditions are safeguarded and intentionally managed, including rules and practices of honour rooted in the society of origin, though without closing ranks to the cultural influences of the country of residence. Therefore, these are certainly ethnic communities, but also transnational ones that act in accordance with powerful social control expectations, especially if the diaspora in question is not scattered but territorialised or has well-defined social spaces in which it carries out its activities. Social control within the family or relatives' group as well as in the diaspora becomes a fundamental social guarantee of the continuity and reproduction of cultural models linked to honour.

It would be a fatal mistake, though, to think that in the country of residence immigrants are so-to-say hemmed in by their own culture of origin, thus also governed by the rules of the code of honour, including its illegal practice such as honour crimes and honour killings in particular. Most immigrants are certainly embedded in their own culture of origin, but do not follow its rules blindly; thus, 
they will not automatically enact the corresponding action strategies. An immigrant will act in accordance with his own culture of origin and in extreme cases will commit a crime such as an honour killing not because he is Muslim, Sikh, Albanian, Turk or Sicilian, but rather because he fears being sanctioned and stigmatised by his significant others. With specific reference to honour in the Mediterranean and contiguous areas, he fears the annihilation of his social status and personal reputation including the good name of his primary group (family and relatives) with the reference community, i.e. his society of origin and diasporic community. This loss of status and good repute often implies negative economic consequences too. Honour and its code are not so much a nearly genetically-set cultural legacy, as much as a system of concrete strategies intentionally put to use in everyday life. Thus, culture, of honour in this specific case, stops being a static entity that the actor cannot escape and becomes a pliant and flexible phenomenon. It proves to be a cultural knowledge, and consequently an adequate action know-how. Therefore, the culture of honour is a social resource for individuals who will both put it to use to assess their own social situation and activate it in specific constellations in order to achieve what is regarded as an opportune goal. On the theme of honour in the Mediterranean area and bordering societies in relation to its criminally relevant aspects in western legal systems, we can observe that it provides the actor with the means to assess the seriousness of the wrongs that he, his family or relatives have suffered and that jeopardise their reputation as well as their social and economic standing. In addition, the code of honour indicates the behaviours needed to restore the former social status, or uphold or improve an unsullied one.

The actual illegal practices enacted by the offended persons, however, are not so much dependent on a blind obedience to social rules, as much as on the assessment of the situation, i.e., whether, in a given circumstance, it would be important or not to conform to the code of honour and commit a criminal offence. Based on my experience as a forensic anthropology expert, realistically speaking, even in a migratory context an honour killing is practically never an automatic and quasi-unwitting act. In these cases it would be misleading to speak of crimes of passion or domestic violence. ${ }^{20}$ Instead, the act is practically always well gauged, whereas culture is not so much a primary cause as much as an instrument put to use competently and rationally. To conclude, in line with Max Weber and Bourdieu we can state that the actors abide by a given rule to the extent that their interest in acting accordingly exceeds their interest in not conforming to said rule. ${ }^{21}$ If on the one hand interests are not universal and ought to be regarded, in a sense, as cultural products, on the other hand actors are not trapped in their social and cultural habitus, which, with reference to specific cultural models, must be regarded as a socially acquired disposition. 
The persistence, spread and normality, however loathsome this may seem, of violent practices linked to the concept of honour are ultimately linked to the modern bureaucratic states' inability to exert their monopoly on the use of physical force within their territory. This powerlessness of the State is noticeable in most societies of origin in which ironbound rules of honour are still in force at a local level, though from a legal-institutional standing certain practices like honour crimes are in principle an indictable offence. When the population involved does not acknowledge the juridical power, then the code of honour - guaranteed by culture, tradition and customary law - will almost inevitably maintain both its meaningfulness and importance. The legal system of these states, which are regarded by their own society as alien and distant, presents a structural weakness and a chronic lack of legitimacy, both rooted in their history. This gives rise to an antiestablishment culture grounded in negative experiences that the populations endured in the past. The outcome of this culture is a legal pluralism with concurrent and at times even conflicting rules between the state's legal system on the one hand, and customary law defining the rules of honour on the other. Under these circumstances of legal dualism, as far as honour crimes are concerned, the two systems are incompatible. In fact, while state law strictly prohibits domestic violence, customary law accepts it or indeed prescribes it. Due to their transnational condition, immigrants often place little trust in the legal system of both state of origin and state of residence; therefore, customary laws, including the ones linked to honour, are followed also in the society of residence.

\section{The Transcultural Aspect of Honour: Conclusions and Recommendations}

In this article we have substantiated that honour is not merely a moral code comprising values, norms, representations, and a set of practices. Rather, it is a cultural idiom and a combination of social strategies found in several public arenas. Yet, believing that honour is typical and exclusive to a specific society would be a serious mistake. The cultural language of honour and its associated behaviours are prevalent in numerous societies, even culturally. Thus, honour in its various expressions in terms of representations and social practices alike is a transcultural phenomenon set up to highlight social differences (class and gender especially), and maintain, increase or restore status and reputation in order to define (better yet, redefine) the social identity of individuals and groups. We need to stress once again that honour, along with its related practices that are often deemed an indictable offence in legal systems of western origin, is not a religion-linked specificity as some neo-orientalist and anti-Islamic authors such as Phyllis Chesler claim instead. The clearest case in point is northern Albania where honour crimes and blood revenge 
are traditionally more widespread among the population's Catholic minority than the Muslim majority.

It would be a serious misjudgement to think that transculturality implies uniformity, thus wiping out honour's cultural specificities. In fact, the concept of honour displays fundamental cultural differences in the various societies mentioned. In modern western societies honour is seen as an utterly personal matter whose management involves only the individual person's sense of responsibility. In other societies, instead, honour has a markedly collective dimension since its maintenance, loss and reestablishment, as highlighted above, involves entire family communities including the extended family, as in the honour killings in line with the practice of blood revenge or feud guaranteed by analogous though culturally-specific forms of customary law. Finally, this type of collective honour is strictly linked to the existence of distinctly patriarchal cultures in which power is concentrated in the hands of male elders and where the principle of patrilineal kinship (often also agnatic), aside from due exceptions, is predominant. Individual honour, instead, generally emerges wherever patriarchal structures are noticeably weakened, whereas bilateral kinship and the nuclear family constitute the norm.

In closing then this article arrives at the following policy recommendations in order to generate understanding of and insight into the complex subject of 'honour':

- Honour needs to be seen as a wider concept that is found in all countries and cultures.

- It should not be considered as tied to religion and not peculiarly to Islam either.

- It is evolving and changeable, but remains an integral part of identity of persons, classes, and communities. It is part of the struggle for recognition.

\section{Notes}

1. The latest and probably most sensational case regarded an attempted 'honour killing' in which a father of Syrian-Orthodox Christian faith with a Swiss citizenship had tried to kill his daughter's Bosnian-Muslim fiancée in accordance with the customary practice in force in Tur Abdin, i.e., his homeland in southeastern Turkey, by which marrying a Muslim is socially unacceptable and a serious offence to the entire family's prestige. See Ulf Björklund, North to Another Country: The Formation of a Suryoyo Community in Sweden, Stockholm (Stockholm: Swedish Commission on Immigration Research EIFO, Stockholm Studies in Social Anthropology, 1981), 72ff.

2. Julian Pitt-Rivers, "Honour", in: International Encyclopedia of the Social Sciences (New York: Macmillan, 1968), 6:503; idem, The Fate of Shechem or the Politics of Sex: Essays in the Anthropology of the Mediterranean (Cambridge et al.: Cambridge University Press, 1977), 1.

3. John G. Peristiany, Honour and Shame: The Values of Mediterranean Society (London: Weidenfeld and Nicolson, 1965), 11. 
4. Carmelo Lison-Tolosana, Belmonte de los Caballeros: A Sociological Study of a Spanish Town (Oxford: Clarendon Press, 1966), 198; John Davis, People of the Mediterranean: An Essay in Comparative Social Anthropology (London: Routledge and Kegan Paul, 1977), 90.

5. Frederick G. Bailey, Gifts and Poison: The Politics of Reputation (Oxford: Blackwell, 1971), 19; Davis, People of the Mediterranean, 99.

6. Pierre Bourdieu, Esquisse d'une théorie de la pratique, précedé de trois études d'ethnologie kabyle (Geneva: Librairie Droz, 1972), 19.

7. Michael Herzfeld, "Honour and Shame: Problems in the Comparative Analysis of Moral Systems", Man, new series, 15 (1980), 339-51.

8. Peristiany, Honour and Shame, 10; Bourdieu, Esquisse, 42.

9. Pitt-Rivers, The Fate of Shechem, 21.

10. John Laffin, Rhetoric and Reality: The Arab Mind Considered (New York: Taplinger Publishing Company, 1975), 90.

11. Bailey, Gifts and Poison.

12. Bourdieu, Esquisse, 239.

13. Pitt-Rivers, The Fate of Shechem.

14. Ibid., 46.

15. Georg Friedrich Wilhelm Hegel, "Phänomenologie des Geistes", in: Werke (Frankfurt am Main: Suhrkamp Taschenbuch Wissenschaft, 1986), 3:145ff.

16. Charles Taylor, Multiculturalism and the 'Politics of Recognition'. An Essay by Charles Taylor with a Commentary by Amy Gutman, Steven C. Rockefeller, Michael Walzer, and Susan Wolf (Princeton, NJ: Princeton University Press, 1992), 37ff.

17. Ibid.

18. Francis Fukuyama, The End of History and the Last Man (New York: Macmillan, 1992); George Ritzer, The McDonaldization of Society: An Investigation into the Changing Character of Contemporary Social Life (London: Thousand Oaks, 1996); idem, The McDonaldization Thesis: Explorations and Extensions (London: Thousand Oaks, 1998); Roland Robertson, "Glocalization: Time-Space and Homogeneity-Heterogeneity", in: Mike Featherstone (ed.), Global Modernities (London: Thousand Oaks, 1995), 25-44; Mike Featherstone, "Global Culture: An Introduction", in: idem (ed.), Global Culture: Nationalism, Globalization and Modernity (London: Thousand Oaks, 1990), 1-14.

19. Pierre Bourdieu and Loïc Wacquant, Reflexive Anthropologie (Frankfurt am Main: Suhrkamp Verlag, 1996).

20. Phyllis Chesler, “Are Honour Killings Simply Domestic Violence?", Middle East Quarterly 16, no. 2 (2009), $61 \mathrm{ff}$.

21. Max Weber, Wirtschaft und Gesellschaft (Tübingen: J.C.B. Mohr \& Paul Siebeck, 1956); Bourdieu and Wacquant, Reflexive Anthropologie. 